\title{
INVERSI MIKROTREMOR UNTUK PROFILING KECEPATAN GELOMBANG GESER (Vs) DAN MIKOROZONASI KABUPATEN BANDUNG
}

\author{
Andina Zuhaera' ${ }^{1}$, Suharno ${ }^{2}$, Bagus S. Mulyatno ${ }^{3}$ \\ 1,2,3 Jurusan Teknik Geofisika, Fakultas Teknik Universitas Lampung \\ Jl. Prof. Soemantri Brodjonegoro No. 01, Bandar Lampung 35145 \\ Corresponding author: andin1215051006@gmail.com \\ Manuscript received: June 30, 2019; revised: July 2, 2019; \\ Approved: July 18, 2019; available online: July 26, 2019
}

\begin{abstract}
Abstrak - Kabupaten Bandung merupakan daerah dataran tinggi dengan kemiringan antara $0-8 \%, 8-15 \%$ hingga di atas $45 \%$. Kabupaten ini terletak pada ketinggian $768 \mathrm{~m}$ di atas permukaan laut dengan daerah utara lebih tinggi dibandingkan daerah sebelah selatan. Tujuan dilakukannya penelitian ini adalah mengetahui sebaran gelombang Vs30 dan mengetahui dampak kerusakan akibat adanya penguatan gelombang (amplifikasi). Untuk memperkecil dampak dari gempabumi ini identifikasi yang dapat dilakukan diantaranya survei untuk memetakan karakteristik tanah dalam merespon guncangan gempabumi menggunakan metode seismik Horizontal to Vertical Spectral Ratio (HVSR). Berdasarkan hasil penelitian persebaran nilai frekuensi dominan, Kabupaten Bandung teridentifikasi memiliki tanah yang keras dan batuan lunak serta memiliki clay padat dengan ketebalan puluhan meter. Nilai amplifikasi di Kabupaten Bandung memiliki nilai $(0<$ Ao $<6)$ yang dapat dikategorikan bahwa Kabupaten Bandung memiliki dampak kerusakan yang kecil terhadap gempabumi. Perbedaan antara hasil pengolahan inversi dan HVSR disebabkan asumsi bahwa pada inversi lapisan bersifat heterogen dan pada HVSR lapisan bersifat homogen.
\end{abstract}

\begin{abstract}
Bandung Regency is a highland area with a slope between $0-8 \%, 8-15 \%$ to above $45 \%$. The district is located at an altitude of $768 \mathrm{~m}$ above sea level with the northern region higher than the south. The purpose of this study was to determine the distribution of Vs30 waves and determine the impact of damage due to wave amplification (amplification). To minimize the impact of this earthquake identification can be done including a survey to map soil characteristics in response to earthquake shocks using the seismic Horizontal to Vertical Spectral Ratio (HVSR) method. Based on the results of the study, the distribution of the dominant frequency values, Bandung Regency was identified as having hard and soft rock soil and having solid clay with a thickness of tens of meters. The amplification value in Bandung Regency has a value $(0<$ Ao $<6)$ which can be categorized that Bandung Regency has a small impact on the earthquake. The difference between the results of inversion processing and HVSR is due to the assumption that the layer inversion is heterogeneous and the HVSR layer is homogeneous.
\end{abstract}

Keywords: microtremor, $\mathrm{Vs}_{30}$, dominant frequency, amplification.

How to cite this article:

Zuhaera, A., Suharno dan Mulyatno, B.S. 2019. Inversi Mikrotremor untuk Profiling Kecepatan Gelombang Geser (Vs) dan Mikorozonasi Kabupaten Bandung. Jurnal Geofisika Eksplorasi, 5 (2) p.89-101.

doi: 10.23960/jge.v5i2.25

\section{PENDAHULUAN}

Bencana alam merupakan suatu rangkaian peristiwa yang disebabkan oleh alam, bersifat mengganggu dan mengancam keberlangsungan hidup manusia. Salah satu bencana alam yang sering kita dengar adalah gempabumi. Gempabumi merupakan getaran atau guncangan yang terjadi di permukaan bumi akibat pelepasan suatu energi dari dalam secara tiba-tiba. Gempabumi disebabkan oleh pelepasan energi yang dihasilkan oleh tekanan yang terus bergerak. 
Indonesia merupakan salah satu negara yang sering mengalami bencana alam gempabumi. Hal tersebut dikarenakan Indonesia berada di daerah pertemuan 3 lempeng tektonik besar, yaitu lempeng Indo-Australia, Eurasia, dan lempeng Pasific.

Untuk mencegah terjadinya kerusakan akibat gempabumi, dapat dilakukan suatu metode HVSR. Dari metode HVSR tersebut akan mendapatkan nilai $\mathrm{V}_{\mathrm{S} 30}$ yang kemudian dikelaskan ke dalam standar NHERP untuk mengetahui kelas tanah pada daerah tersebut seperti pada penelitian (Athanasius dan Solikhin, 2015).

Seperti pada penelitian (Netrisa dkk, 2018) besar nilai $V_{S 30}$ tergantung pada parameter jenis tanah dan didasarkan untuk penentuan kelas tanah. Analisis kecepatan gelombang geser dapat mengetahui potensi kerusakan apabila gempabumi terjadi.

Salah satu wilayah yang berpotensi terjadi gempabumi adalah Kabupaten Bandung, Jawa Barat. Hal tersebut disebabkan adanya patahan atau sesar lembang di utara Kota Bandung. Patahan tersebut muncul akibat adanya aktifitas tektonik. Berdasarkan keadaan geologis tersebut, maka dilakukanlah penelitian ini untuk meminimalisir efek yang ditimbulkan oleh gempabumi tersebut.

\section{TINJAUAN PUSTAKA}

Penilitian ini dilakukan di daerah Bandung yang merupakan ibukota dari provinsi Jawa Barat. Secara geografis, Bandung terletak pada koordinat $107^{\circ} 14^{\prime}$ $107^{\circ} 56^{\prime}$ BT dan 6 $6^{\circ} 49^{\prime}$ - $7^{\circ} 18^{\prime}$ LS. Kabupaten Bandung termasuk wilayah dataran tinggi dengan kemiringan lereng antara $0-8 \%, 8-15 \%$, hingga di atas $45 \%$. Sebagian besar wilayah Kabupaten Bandung berada diantara bukit-bukit dan gunung-gunung.

Kabupaten Bandung terletak pada ketinggian $\pm 768 \mathrm{~m}$ di atas permukaan ratarata mean sea level. Dengan daerah utara pada umumnya lebih tinggi daripada di bagian selatan. ketinggian di sebelah utara adalah $\pm 1050 \mathrm{msl}$, sedangkan di bagian selatan adalah $\pm 675 \mathrm{msl}$.

\subsection{Fisiografi Daerah Penelitian}

Secara umum daerah Jawa Barat dibagi menjadi tiga wilayah, yaitu wilayah utara, tengah, dan selatan. wilayah selatan merupakan dataran tinggi dan pantai, wilayah tengah merupakan wilayah pegunungan, sedangkan wilayah utara merupakan dataran rendah.

Dan secara fisiografi Jawa Barat dibagi menjadi empat zona berarah barat-timur yaitu Zona Dataran Pantai Jakarta, Zona Bogor, Zona Bandung, dan Zona Pegunungan Selatan Jawa Barat (van Bemmelen, 1949).

\section{TEORI DASAR}

\subsection{Mikrotremor}

Mikrotremor merupakan getaran tanah yang ditimbulkan oleh peristiwa alam ataupun buatan, misal angin, gelombang laut, atau getaran kendaraan, yang dapat menggambarkan kondisi geologi dekat permukaan. Mikrotremor mempunyai frekuensi lebih tinggi dari frekuensi gempa bumi, periodenya kurang dari 0,1 detik yang secara umum antara 0,05-2 detik dan untuk mikrotremor periode panjang bisa 5 detik, sedang amplitudenya berkisar 0,1-2,0 mikron (Tokimatsu, 1995).

\subsection{Metode HVSR}

Metode HVSR merupakan metode membandingkan spektrum komponen horizontal terhadap komponen vertikal dari gelombang mikrotremor. Mikrotremor terdiri dari ragam dasar gelombang Rayleigh, periode puncak perbandingan $H / V$ mikrotremor memberikan dasar dari periode gelombang $\mathrm{S}$ (S-wave). Perbandingan $H / V$ pada mikrotremor merupakan perbandingan dua komponen yang secara teoritis menghasilkan suatu nilai. Metode HVSR digunakan untuk menentukan nilai amplifikasi dan nilai 
periode dominan suatu lokasi yang dapat diperkirakan dari periode puncak perbandingan $H / V$ mikrotremor (Nakamura, 2000).

Nakamura (1989) mengidentifikasi bahwa jika diasumsikan gelombang geser dominan pada mikrotremor, maka rasio spektrum horisontal terhadap vertikal (HVSR) pada data mikrotremor suatu tempat sama dengan fungsi transfer gelombang geser yang bergetar antara permukaan dan batuan dasar di suatu tempat.

\subsection{Frekuensi Dominan}

Frekuensi dominan adalah nilai frekuensi yang kerap muncul sehingga diakui sebagai nilai frekuensi dari lapisan batuan di wilayah tersebut sehingga nilai frekuensi dapat menunjukkan jenis dan karakterisktik batuan tersebut. Lachet dan Brad (1994) melakukan uji simulasi dengan menggunakan 6 model struktur geologi sederhana dengan kombinasi variasi kontras kecepatan gelombang geser dan ketebalan lapisan sedimen. Hasil simulasi menunjukkan nilai puncak frekuensi berubah terhadap variasi kondisi geologi.

Dari nilai frekuensi dominan yang terukur dipermukaan, dapat diketahui karakteristik batuan di bawahnya, hal tersebut dapat dilihat pada Tabel 1 tentang klasifikasi tanah berdasarkan nilai frekuensi dominan oleh Kanai (1998).

\subsection{Kecepatan Gelombang Geser (Vs30)}

Kemiringan lereng (slope) dapat mengindikasikan ketebalan lapisan sedimen. Material hasil pelapukan akan diendapkan lebih tebal pada bagian yang mempunyai kemiringan lereng lebih kecil. Material sedimen di lereng akan jauh lebih tipis dibandingan dengan endapan sedimen dalam suatu cekungan. Oleh sebab itu, pada elevasi yang tinggi dan kemiringan lereng yang curam, nilai $V_{S 30}$ relatif lebih kecil karena pada daerah tersebut didominasi batuan yang keras. Hasil perhitungan $\mathrm{V}_{\mathrm{S} 30}$ kemudian dikelaskan ke dalam standar NHERP untuk mengetahui kelas tanah pada daerah tersebut (Athanasius dan Solikhin, 2015).

Analisis kecepatan gelombang geser dapat mengetahui potensi kerusakan apabila terjadi gempabumi. Hal ini disebabkan karena dampak kerusakan suatu tempat gempabumi tidak hanya berdasarkan jarak episenter dan besar kekuatan gempa, tetapi juga kondisi lokal daerah setempat. Salah satu metode yang dapat menggambarkan kondisi lokal daerah setempat adalah pemetaan nilai kecepatan gelombang geser $\left(\mathrm{V}_{\mathrm{S} 30}\right)$. Goncangan lebih kuat terjadi pada daerah dengan nilai $\mathrm{V}_{\mathrm{S} 30}$ yang rendah (Susilanto dan Ngadmanto, 2015).

\subsection{Amplifikasi}

Amplifikasi merupakan perbesaran gelombang seismik yang terjadi akibat adanya perbedaan yang signifikan antar lapisan, dengan kata lain gelombang seismik akan mengalami perbesaran, jika merambat pada suatu medium ke medium lain yang lebih lunak dibandingkan dengan medium awal yang dilaluinya. Semakin besar perbedaan itu, maka perbesaran yang dialami gelombang tersebut akan semakin besar. Pada batuan yang sama, nilai amplifikasi dapat bervariasi sesuai dengan tingkat deformasi dan pelapukan pada tubuh batuan tersebut (Marjiyono, 2010).

Nilai faktor penguatan (amplifikasi) tanah berkaitan dengan perbandingan kontras impedansi lapisan permukaan dengan lapisan di bawahnya. Bila perbandingan kontras impedansi kedua lapisan tersebut tinggi maka nilai faktor penguatan juga tinggi, begitu pula sebaliknya (Nakamura, 2000).

\section{METODOLOGI PENELITIAN}

Penelitian menggunakan data sekunder yang diperoleh dari Pusat Vulkanologi dan Mitigasi Bencana Geologi (PVMBG) pada tahun 2016 yang diolah menggunakan software geopsy untuk mendapatkan frekuensi dominan dan software HV explorer untuk melakukan inversi. Pada 
penelitian ini hal yang pertama dilakukan adalah mengolah data menggunakan software geopsy untuk mendapatkan nilai frekuensi dominan yang kemudian nilai frekuensi dominan tersebut digunakan untuk menganalisa nilai periode dominan, $\mathrm{V}_{\mathrm{S} 30}$, dan amplifikasi.

Secara rinci, metodologi penelitian dapat dilihat pada Gambar 1.

\section{HASIL DAN PEMBAHASAN}

\subsection{Analisis Persebaran Nilai Frekuensi Dominan}

Berdasarkan hasil pengukuran pada Gambar 2. di Kabupaten Bandung, daerah ini memiliki nilai frekuensi dominan 4 jenis. Namun sebagian besar wilayah ini memiliki nilai frekuensi dominan $<2,5 \mathrm{~Hz}$ yang artinya memiliki ketebalan lapisan sedimen yang sangat tebal yaitu $>30 \mathrm{~m}$. Berdasarkan tabel klasifikasi tanah oleh Kanai pada Tabel 1. Daerah ini memiliki batuan aluvial yang terbentuk dari sedimentasi delta, top soil, dan lumpur

Daerah yang memiliki nilai frekuensi ini ditunjukkan dengan warna biru tua adalah Kecamatan Ciparay, Kecamatan Majalaya, Kecamatan Bojongsoang, Kecamatan Cikandung, Kecamatan Paseh, sebagian besar Kecamatan Rancaekek, sebagian besar Kecamatan Bale Endah, dan sebagian besar Kecamatan Arjasari.

\subsection{Analisis Persebaran Nilai Periode Dominan}

Periode dominan dapat menunjukkan karakteristik material penyusun lapisan tanah, serta memiliki kaitan erat dengan kedalaman lapisan sedimen. Periode dominan yang tinggi dapat mengindikasikan adanya lapisan sedimen lunak yang tebal, periode dominan yang rendah mengindikasikan adanya lapisan sedimen lunak yang tipis. Periode dominan berbanding lurus dengan penguatan gelombang, sehingga daerah dengan periode dominan tinggi umumnya memiliki kerentanan untuk mengalami kerusakan yang tinggi ketika terjadi gempa bumi.

Kabupaten Bandung yang memiliki nilai periode dominan tinggi ditandai dengan warna merah pada Ganbar 3 berada di Kecamatan Pameungpeuk, Kecamatan Bale Endah, Kecamatan Bojongsoang, Kecamatan Ciparay, Kecamatan Majalaya, Kecamatan Rancaekek, Kecamatan Cikandung, Kecamatan Paseh, dan Kecamatan Cileunyi. Untuk daerah lainnya memiliki nilai antara $0,1 \mathrm{~s}-0,4 \mathrm{~s}$.

\subsection{Analisis Persebaran Nilai Vs30}

Nilai Vs30 akan selalu berbanding lurus dengan nilai frekuensi dominan dan ketebalan sedimen. Dari peneitian ini menggunakan asumsi bahwa ketebalan lapisan adalah $30 \mathrm{~m}$. Berdasarkan Gambar 4. dapat diketahui bahwa nilai $\mathrm{Vs}_{30}>804$ $\mathrm{Hz}$ terdapat pada Kecamtan Dayeuh Kolot dan serbagian kecil Kecamatan Marga Asih dan Margahayu. Berdasarkan Tabel 1. Daerah ini memiliki lapisan batuan yang keras.

Untuk nilai $\mathrm{Vs}_{30} 480$ - $804 \mathrm{~Hz}$ terdapat di Kecamatan Marga Asih, Kecamatan Margahayu, Kecamatan Cilengkrang, sebagian Kecamatan Cimenyan dan sebagian kecil Kecamatan Soreang. Berdasarkan Tabel 1. Daerah ini memiliki endapan sand atau clay yang padat, gravel, pada ketebalan puluhan meter yang ditandai dengan penigkatan sifat mekanik terhadap kedalaman.

Untuk nilai Vs 30300 - $480 \mathrm{~Hz}$ terdapat di sebagian besar Kecamatan Soreang, Kecamatan Pameungpeuk, sebagian besar Kecamatan Banjaran, sebagian Kecamatan Arjasari, sebagian besar Kecamatan Rancaekek dan sebagian besar Kecamatan Majalaya. Berdasarkan Tabel 1. Lapisan ini memiliki tanah yang keras dan batuan lunak serta memiliki clay padat dengan ketebalan puluhan meter.

Nilai $\mathrm{Vs}_{30}<300 \mathrm{~Hz}$ terdapat di Kecamatan Ciparay, Kecamatan Majalaya, Kecamatan Bojongsoang, Kecamatan Cikandung, Kecamatan Paseh, sebagian besar Kecamatan Rancaekek, sebagian 
besar Kecamatan Bale Endah, dan sebagian besar Kecamatan Arjasari berdasarkan Tabel 1. Daerah ini memiliki sand padat atau setengah padat yang tebal, gravel atau clay padat dengan ketebalan puluhan hingga ratusan meter.

\subsection{Analisis Persebaran Nilai Amplifikasi \\ Berdasarkan peta sebaran pada} Gambar 5. Dapat diketahui bahwa sebagian besar Kabupaten Bandung memiliki nilai amplifikasi yang rendah. Nilai amplifikasi yang besar terdapat pada daerah yang memiliki nilai $\mathrm{Vs}_{30}<300 \mathrm{~Hz}$ memiliki nilai $3-6$ kali yaitu pada Kecamatan Bojongsoang, sebagian Kecamatan Rancaekek, Kecamatan Ciparay, dan sebagian Kecamatan Cikandung.

Untuk nilai $\mathrm{Vs}_{30}$ di atas $300 \mathrm{~Hz}$ memiliki nilai amplifikasi yang lebih kecil yaitu $0-3$ kali. Daerah tersebut adalah Kecamatan Margoasih, Kecamatan Soreang, Kecamatan Margahayu, Kecamatan Katapang, Kecamatan Pameungpeuk, Kecamatan Dayeuhkolot, Kecamatan Banjaran, Kecamatan Arjasari, Kecamatan Ciparay, Kecamatan Majalaya, Kecamatan Cileunyi, Kecamatan Rancaekek, Kecamatan Paseh, dan Kecamatan Cikandung. Dengan demikian dapat diartikan bahwa Kabupaten Bandung memiliki dampak kerusakan yang kecil terhadap gempabumi.

\section{KESIMPULAN DAN SARAN}

\subsection{Kesimpulan}

Kesimpulan yang diperoleh dari penelitian ini adalah sebagai berikut:

1. Persebaran nilai frekuensi dominan di Kabupaten Bandung memiliki nilai $\left(0,705 \leq f_{o} \leq 9,932 \mathrm{~Hz}\right)$ yang mengindikasikan bahwa sebagian besar Kabupaten Bandung memiliki ketebalan sedimen $10-30 \mathrm{~m}$, dan sebagian lainnya memiliki batuan keras.

2. Periode dominan di Kabupaten Bandung didominasi dengan nilai < 0,57s yang memiliki lapisan sedimen yang lunak.

3. Nilai $\mathrm{Vs}_{30}$ di Kabupaten Bandung di dominasi dengan nilai $\left(72,475 \leq \mathrm{Vs}_{30} \leq\right.$ $696,627 \mathrm{~Hz}$ ) yang mengindikasikan bahwa lapisan di Kabupaten Bandung memiliki tanah yang keras dan batuan lunak serta memiliki clay padat dengan ketebalan puluhan meter.

4. Nilai amplifikasi di Kabupaten Bandung memiliki nilai $(0,557 \leq$ Ao $\leq$ 5,307 kali) yang dapat dikategorikan bahwa Kabupaten Bandung memiliki dampak kerusakan yang kecil terhadap gempabumi.

\subsection{Saran}

Saran yang dapat diberikan berdasarkan penelitian tersebut adalah:

1. Diperlukan data sampel coring untuk memvalidasi ketebalan sedimen hasil inversi HVSR.

2. Diperlukan penelitian lanjutan menggunakan metode MASW (Multi Chanel Surface Wave Method) atau Seismik Refraksi untuk membuktikan ketebalan sedimen yang sebenarnya.

\section{UCAPAN TERIMAKASIH}

Penulis mengucapkan terimakasih kepada Allah SWT, yang telah memberikan hidayah dan petuahnya sehingga karya tulis ini dapat diselesaikan. Dan tak lupa penulis juga mengucapkan terimakasih kepada Ayah dan Ibu atas dukungan dan motivasinya serta naasehat baik yang telah diberikan kepada penulis.

\section{DAFTAR PUSTAKA}

Athanasius, C., dan Solikhin, A., 2015, Pendugaan Kecepatan Gelombang Permukaan (VS30) di Pulau Sulawesi Berdasarkan Klasifikasi Geomorfologi dan Aplikasinya, Bandung: PVMBG. 
Kanai, K., 1998. Seismology in Engineering, Japan: Tokyo University.

Lachet, C., dan Brad, P.Y., 1994, Numerical and Theoretical Investigations on The Possibilities and Limitations of Nakamura's Technique, J. Phys Earth, Vol. 42, pp. 377-397.

Marjiyono, 2010, Estimasi Karakteristik Dinamika Tanah Dari Data Mikrotremor Wilayah Bandung, Bandung: Thesis ITB.

Nakamura, Y., 1989, A method for dynamic characteristics estimation of subsurface using microtremor on the ground surface, Tokyo: Quatrely Reports of the Railway Technical Research Institute.

Nakamura. Y., 2000, Clear Identification of Fundamental Idea of Nakamura's Technique and Its Application, Japan: Tokyo University.

Netrisa, Z., Syafriani., Triyono, R., dan Arifin, H., 2018, Pemetaan Bahaya Gempabumi Determinitik Dengan Pendekatan PGA Di Kota Padang. Pillar of Physics, Vol.11 No. 2, pp. 4148.

Susilanto, P., dan Ngadmanto, D., 2015, Analisis Kecepatan Gelombang Geser $\left(\mathrm{V}_{\mathrm{S}}\right)$ di Cilacap, Jawa Tengah sebagai Upaya Mitigasi Gempabumi, Jurnal Meteorologi dan Geofisika (JMG) Vol 16 No 1, pp. 57-64.

Tokimatsu, K., 1995, Geotechnical Site Characterization Using Surface Waves, Japan: Geotechnical Engineering.

van Bemmelen, R. W., 1949, The Geology of Indonesia, I.A: Government Printing Office. 


\section{LAMPIRAN}

Tabel 1. Klasifikasi Batuan berdasarkan nilai frekuensi dominan oleh Kanai (1998)

\begin{tabular}{|c|c|c|c|c|}
\hline \multicolumn{2}{|c|}{$\begin{array}{c}\text { Klasifikasi } \\
\text { Tanah }\end{array}$} & \multirow{2}{*}{$\begin{array}{c}\text { Frekuensi } \\
\text { Dominan } \\
(\mathbf{H z}) \\
\end{array}$} & \multirow[t]{2}{*}{ Klasifikasi Kanai } & \multirow[t]{2}{*}{ Deskripsi } \\
\hline Tipe & Jenis & & & \\
\hline \multirow{2}{*}{$\begin{array}{l}\text { Tipe } \\
\text { IV }\end{array}$} & Jenis I & $6,667-20$ & $\begin{array}{c}\text { Batuan tersier atau } \\
\text { lebih tua. Terdiri dari } \\
\text { batuan Hardy Sandy, } \\
\text { gravel, dll }\end{array}$ & $\begin{array}{l}\text { Ketebalan sedimen } \\
\text { permukaannya sangat } \\
\text { tipis, didominasi oleh } \\
\text { batuan keras }\end{array}$ \\
\hline & Jenis II & $4-10$ & $\begin{array}{l}\text { Batuan alluvial, } \\
\text { dengan ketebalan } 5 \mathrm{~m} \text {. } \\
\text { Terdiri dari sandy- } \\
\text { gravel, sandy hard } \\
\text { clay, loam, dll }\end{array}$ & $\begin{array}{c}\text { Ketebalan sedimen } \\
\text { permukaannya masuk } \\
\text { dalam kategori } \\
\text { menengah } 5-10 \mathrm{~m}\end{array}$ \\
\hline $\begin{array}{l}\text { Tipe } \\
\text { III }\end{array}$ & $\begin{array}{c}\text { Jenis } \\
\text { III }\end{array}$ & $2,5-4$ & $\begin{array}{c}\text { Batuan alluvial, } \\
\text { dengan ketebalan }> \\
5 \mathrm{~m} . \text { Terdiri dari } \\
\text { sandy-gravel, sandy } \\
\text { hard clay, loam, dll }\end{array}$ & $\begin{array}{l}\text { Kategori sedimen } \\
\text { permukaan masuk } \\
\text { dalam kategori tebal, } \\
\text { sekitar } 10-30 \mathrm{~m}\end{array}$ \\
\hline $\begin{array}{l}\text { Tipe } \\
\text { II }\end{array}$ & & & $\begin{array}{c}\text { Batuan alluvial yang } \\
\text { terbentuk dari }\end{array}$ & \\
\hline Tipe I & $\begin{array}{c}\text { Jenis } \\
\text { IV }\end{array}$ & $<2,5$ & $\begin{array}{l}\text { sedimentasi delta, top } \\
\text { soil, lumpul, dll. } \\
\text { Dengan kedalaman } 30 \\
\text { m atau lebih }\end{array}$ & $\begin{array}{l}\text { Ketebalan sedımen } \\
\text { permukaannya } \\
\text { sangatlah tebal }\end{array}$ \\
\hline
\end{tabular}




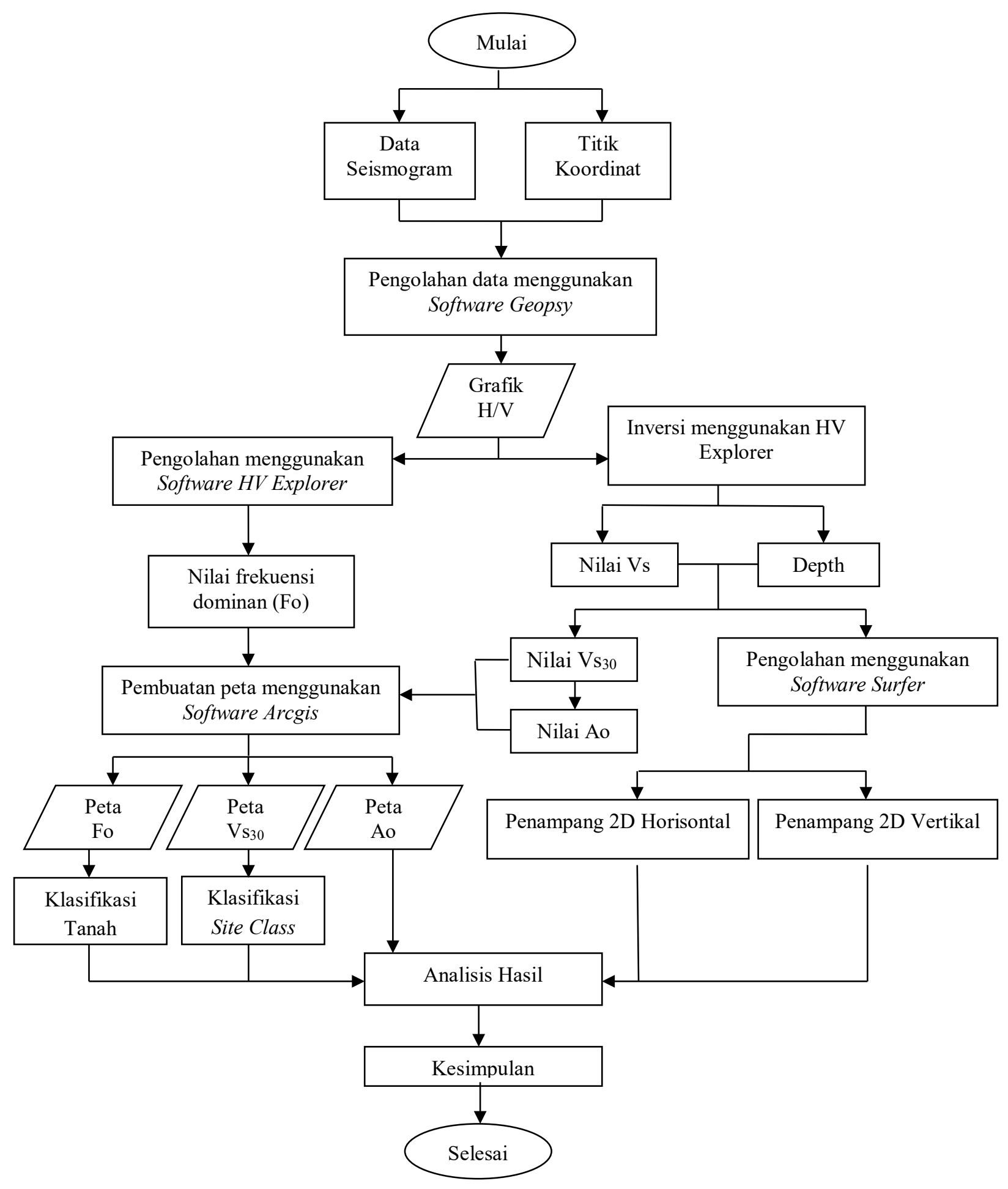

Gambar 1. Diagram Alir Penelitian 


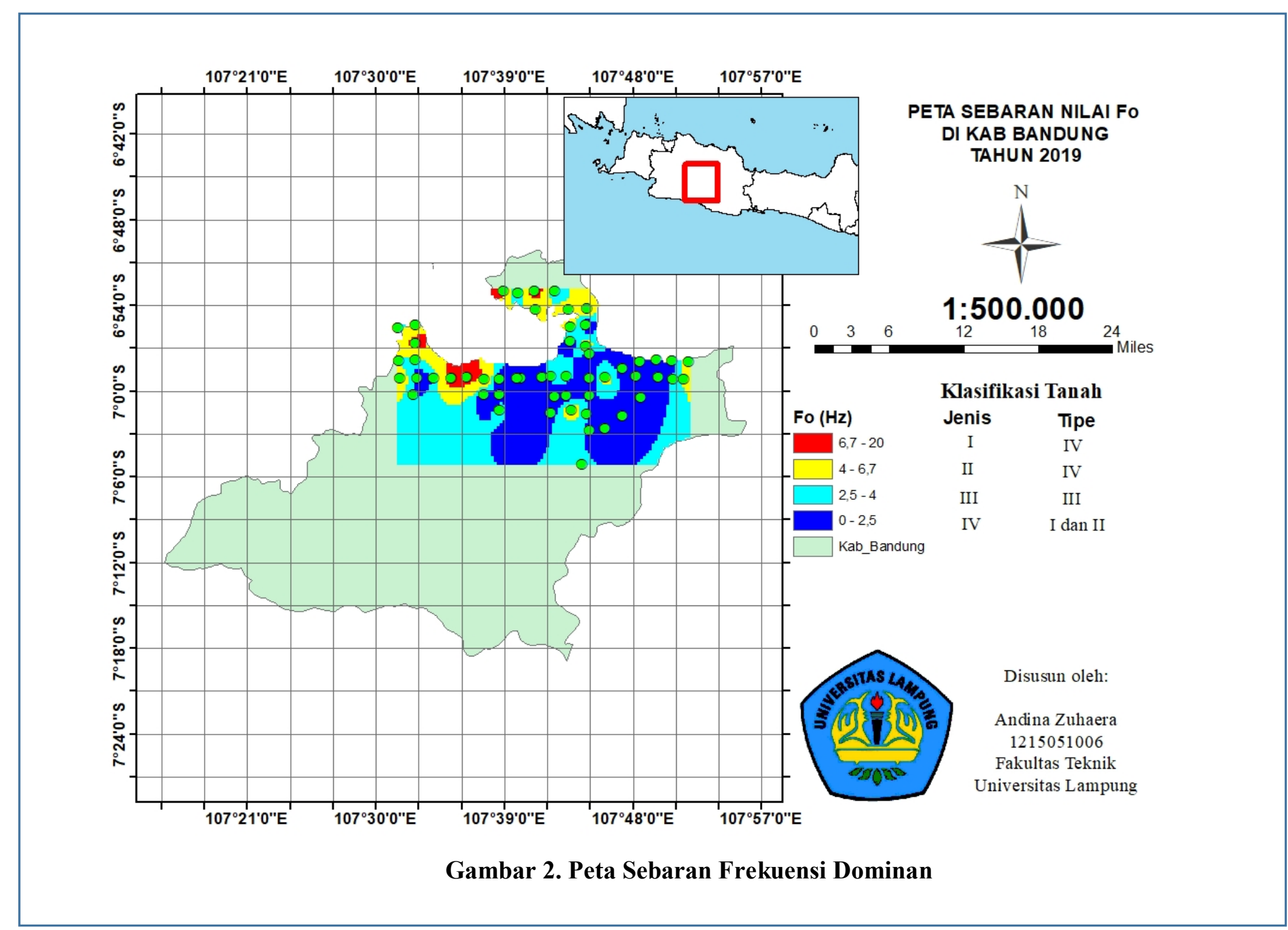




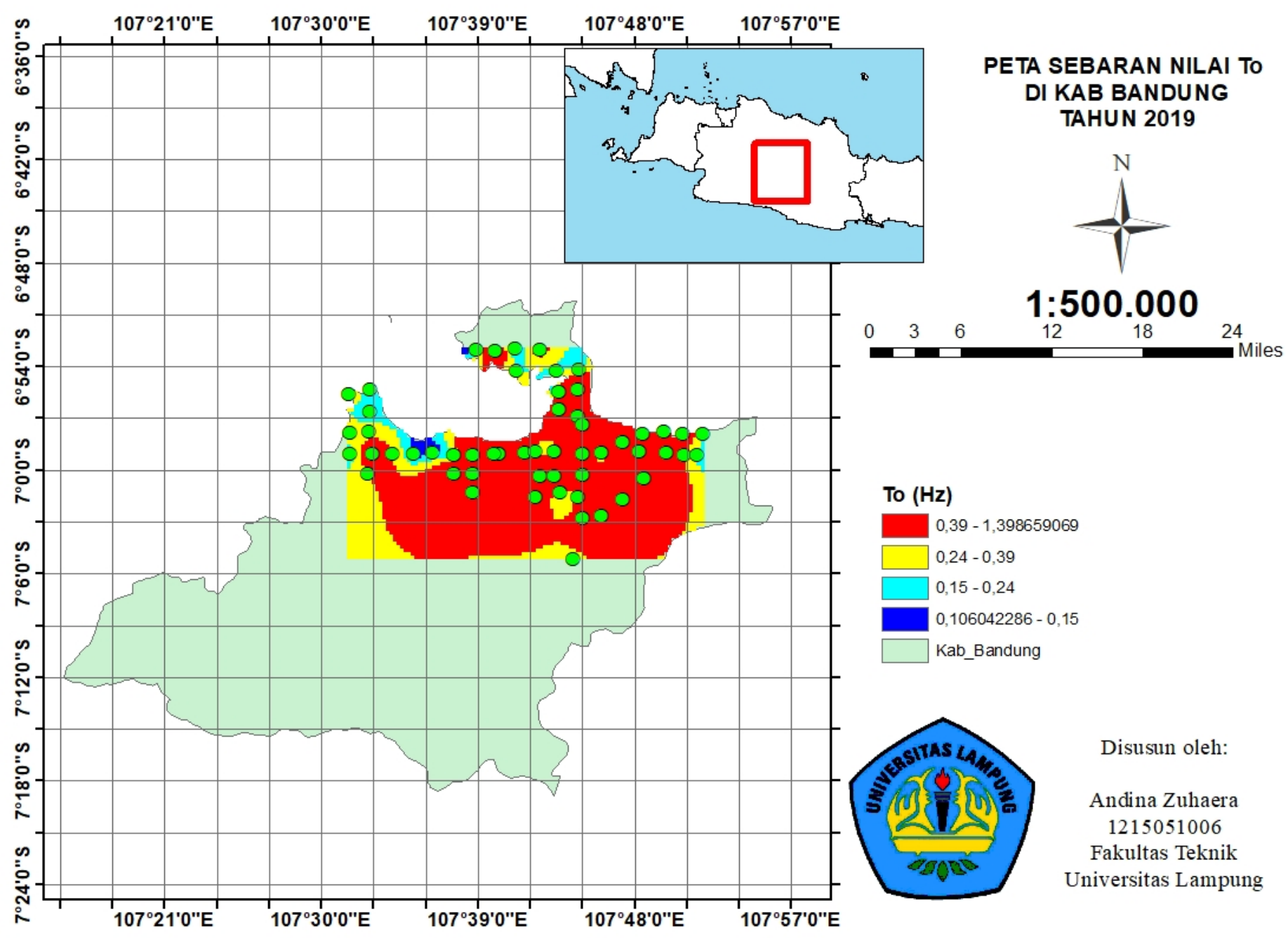

Gambar 3. Peta Sebaran Nilai Periode Dominan 


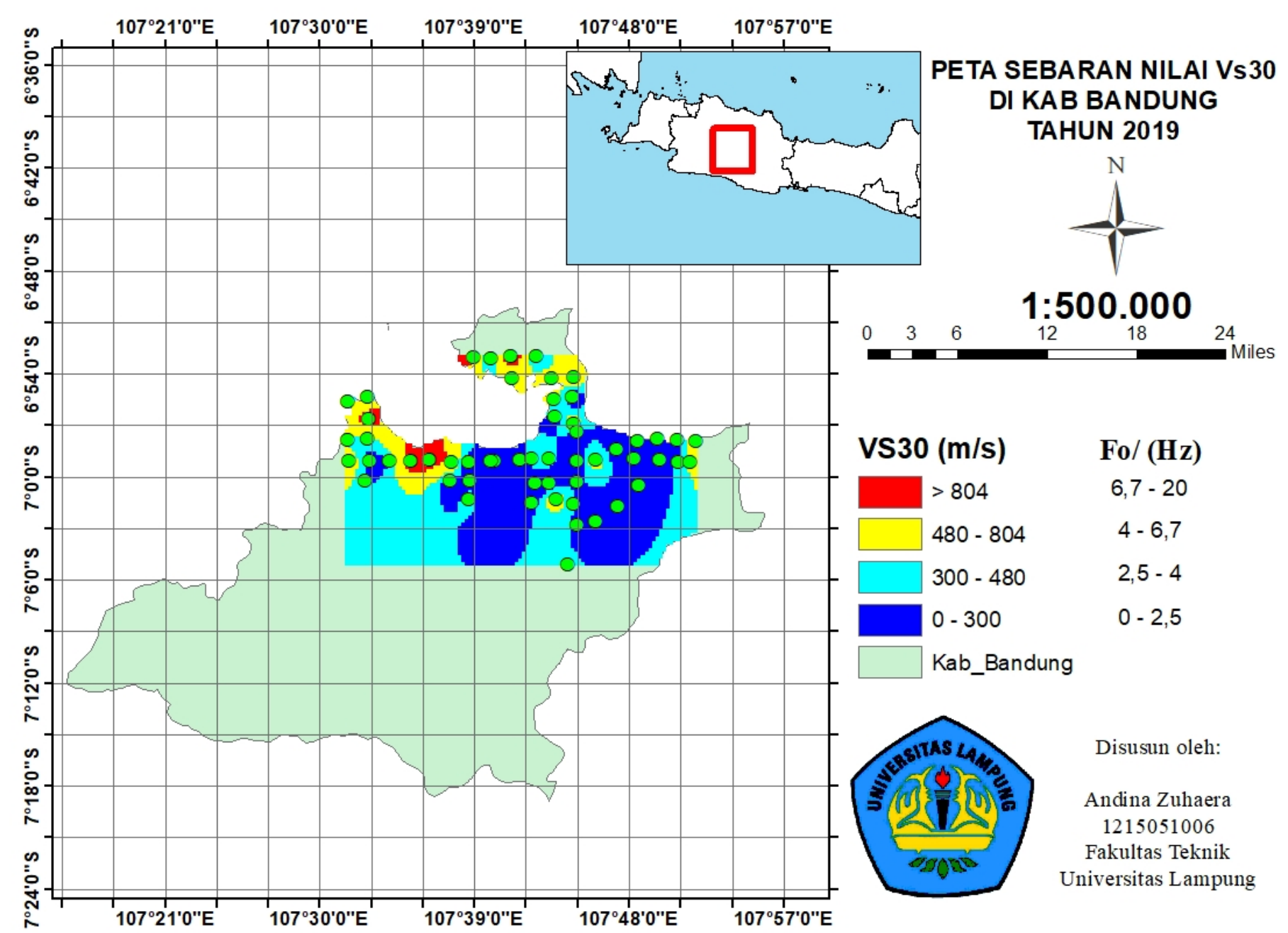

Gambar 4. Peta Sebaran Nilai Vs30 


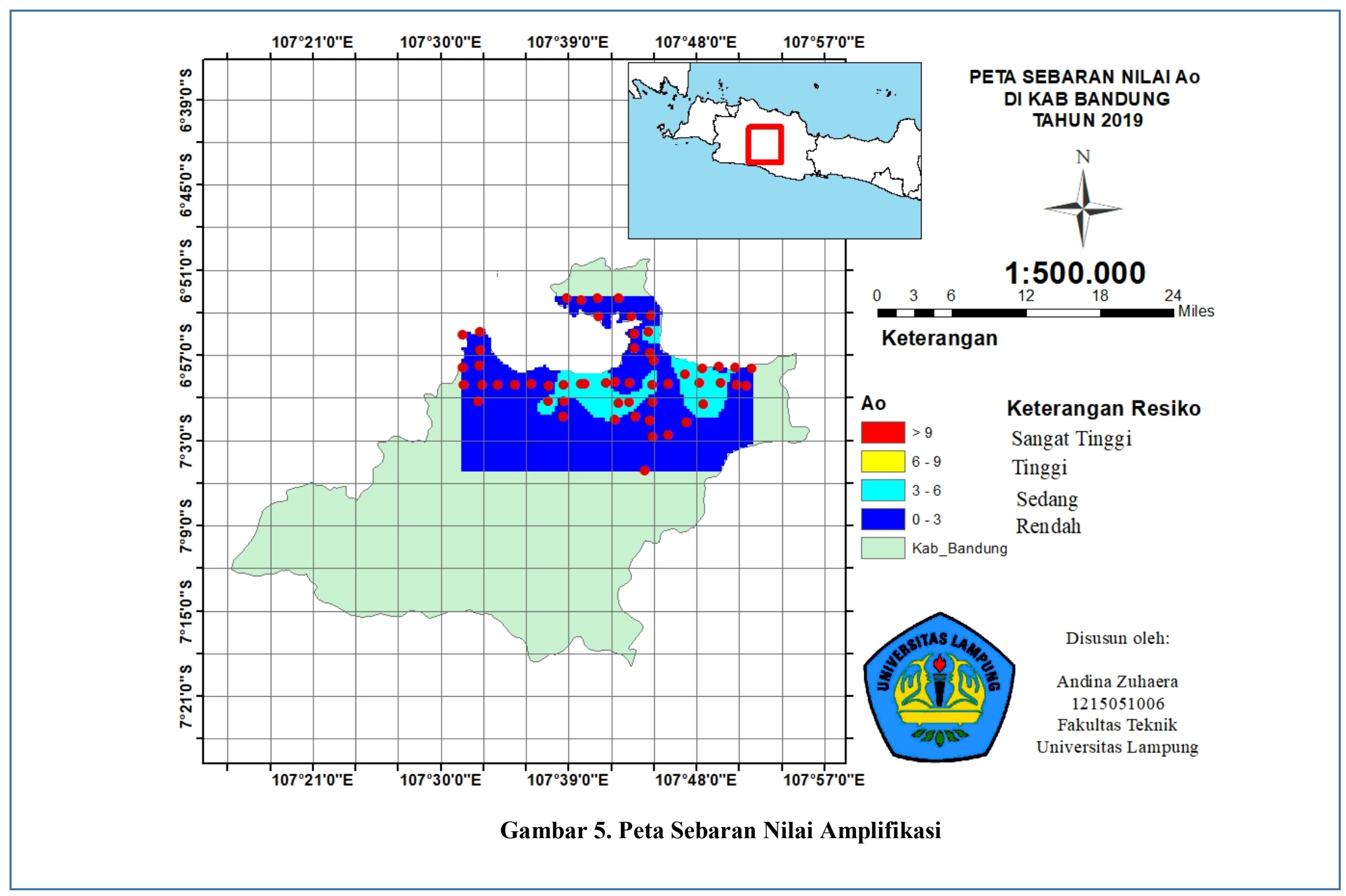

